\title{
RESPIRATORY IMPACT OF ELECTRONIC CIGARETTES AND "LOW-RISK” TOBACCO
}

\author{
Ireri Thirión-Romero ${ }^{1}$, Rogelio Pérez-Padilla ${ }^{1}$, Gustavo Zabert² and IntI Barrientos-Gutiérrez ${ }^{3 *}$ \\ ${ }^{1}$ Department of Research in Tobacco and COPD, Instituto Nacional de Enfermedades Respiratorias Ismael Cosío \\ Villegas, Mexico City, Mexico; ${ }^{2}$ Facultad de Ciencias Médicas, Universidad Nacional del Comahue, Cipolletti, Río Negro, \\ Argentina; ${ }^{3}$ Department of Tobacco Research, Center for Population Health Research, Instituto Nacional de Salud \\ Pública, Cuernavaca, Mexico
}

\begin{abstract}
Electronic cigarettes, handheld devices that generate an aerosol that may contain nicotine by heating a solution or e-liquid, have been increasingly used especially in the young population. The aerosol's composition is determined by temperature, and by the substances contained in the heated liquid: glycerin, propylene glycol, nicotine in variable concentrations, flavoring agents, and other non-nicotine compounds. >80 compounds (including known toxics, e.g., formaldehyde, acetaldehyde, metallic nanoparticles, and acrolein) have been found in e-liquid and aerosols. Airway irritation, mucus hypersecretion, and inflammatory response, including systemic changes, have been observed after the exposure to e-cigarettes, leading to an increase in respiratory symptoms and changes in respiratory function and the host defense mechanisms. E-cigarette has been linked with an increase of symptoms in individuals with asthma, cystic fibrosis, and chronic obstructive pulmonary disease. One of the major concerns in public health is the rise in e-cigarette experimentation among never-smokers, especially children and adolescents, which leads to nicotine addiction and increases the chances of becoming with time a conventional smoker. There is an urgent need to regulate e-cigarettes and electronic nicotine delivery systems, at least with the same restrictions to those applied to tobacco products, and not to consider them as harmless products. (REV INVEST CLIN. 2019;71:17-27)
\end{abstract}

Key words: Chronic obstructive pulmonary disease. Tobacco. E-cigarettes. Lung health.

\section{INTRODUCTION}

Electronic cigarettes, also known as "e-cigarettes," "e-cigs," "cigalikes," "e-hookahs," "mods," "vape pens," "vapes" or "tank systems," refer to a device that delivers nicotine through the respiratory system, thus their proposed technical name of electronic nicotine delivery system (ENDS) ${ }^{1,2}$. A recently released ENDS, launched by Phillip Morris as IQOS, was designed to produce an aerosol by heating tobacco without burning it. This "heat-not-burn" device is a novel ENDS different from e-cigs. ENDS not only disembarked widely in the tobacco consumer's market but also has introduced a wedge in the scientific smoking-cessation and tobacco-control advocacy communities.

\section{Corresponding author:}

*Inti Barrientos-Gutiérrez

Department of Tobacco Research

Center for Population Health Research

National Institute of Public Health

Received for publication: 02-06-2018

C.P. 62100, Cuernavaca, Mor., Mexico

E-mail: inti.barrientos@insp.mx 
Figure 1 . Structure of an e-cigarette. E-cigarettes have some basic components as shown, although new generations have changed considerably the shape. Most current models differ considerably from a cigarette. 1: Battery: usually rechargeable, and as other batteries with the possibility of leaks and explosions. 2: Heating coil: amount of vapor depends on temperature, and new devices can modify it. 3: Vaporizing chamber: includes a wick in touch with e-liquid, with different flavors and nicotine content. 4: Mouthpiece.

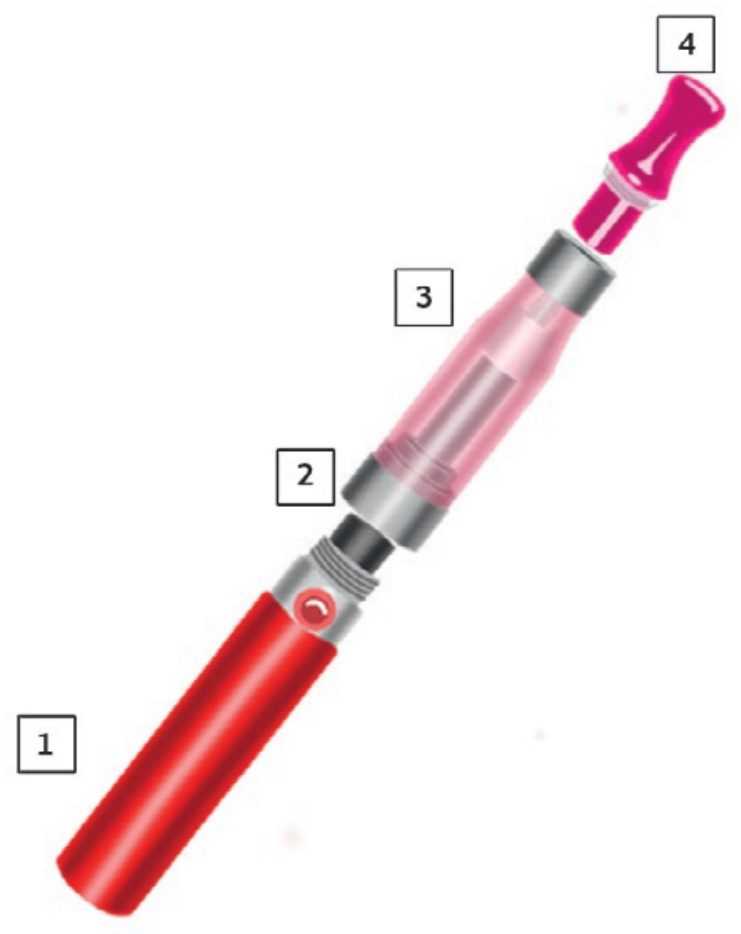

The first commercially available e-cigs device was developed in China, in 2003, as an alternative to smoking in places where smoking regular cigarettes were prohibited $^{3,4}$. It was named Ruyan, a Chinese word for "resembling smoking," and unlike nicotine patches, gum or lozenges it was not designed as a pharmacologic tool for smoking cessation but to deliver "enjoyable" nicotine and overcome regulations ${ }^{5}$.

E-cigs are by definition handheld devices that generate an aerosol, improperly named as "vapor," by heating a solution or e-liquid. The generic e-cig is a batterypowered device that heats a metal coil to atomize the e-liquid drawn by wicks, typically made of cotton or silica, from a cartridge or a refilling reservoir ${ }^{1,2,4}$. Although e-cigs are diverse in terms of design, technology, and liquid filling system, they all operate similarly. Activation is triggered by pressing a button or by airflow sensor in the mouthpiece so that the generated vapor is disposed by inhalation into the respiratory system, resulting in variable exposures, deposition, and absorption depending on the composition, device and inhalation patterns ${ }^{1,2}$ (Fig. 1).

Composition of the aerosol, particles suspended in gas, is determined by temperature and the substances contained in the heated liquid. E-liquids are solutions that contain vegetable glycerin (VG), propylene glycol (PG), nicotine in variable concentrations, flavoring agents, and other non-nicotine compounds ${ }^{2,4}$. Up to 7700 different flavoring components in e-cigarettes have been described in the market ${ }^{1}$.

Although manufacturers have proposed standardization for e-liquid, they offer scarce accurate information about the chemical components in the e-liquid and the e-cigarette aerosol ${ }^{1,6}$. $>80$ compounds have been found in e-liquid and aerosols, while PG and VG are the liquid vehicle through which the heating process generates formaldehyde, acetaldehyde, and acrolein by pyrolysis. Other identified substances are nicotine, acetone, benzaldehyde, siloxanes, reactive oxygen species, volatile organic compounds, polycyclic aromatic hydrocarbons, and tobacco-specific nitrosamines (TSNAs), including $\mathrm{N}$-nitrosonornicotine $(\mathrm{NNN})^{2,6,7}$. Even when the nicotine concentration, as well as that of other components, is listed on the labels of e-cigarette cartridges and refill solutions, large differences have been described between brands, and in some e-liquids labeled as "no nicotine," a high nicotine content was found. Total TSNAs, NNN, nicotine-derived nitrosamine ketone (NNK), and $\mathrm{N}^{\prime}$-nitrosoanatabine have also been found with 3 order of magnitude variation between different brands. Nickel-chromium, chromium-aluminum-iron, copper, silver, zinc, tin, or manganese have been described as metal nanoparticles in the e-liquid and vapor as toxins resulting from the device's components and the heating process. Nickel contained in the e-cig aerosol was 2-100 times higher than in tobacco smoke $^{8}$.

E-cigarette aerosol is not produced by combustion. Therefore, neither smoke nor carbon monoxide is emitted. Although there is no side steam vapor, in chamber studies and model café environments, a low level of most of the vapor components can be found in the air ${ }^{9}$. Furthermore, serum cotinine was similar in 
non-smoking bystanders' exposure to aerosol and smokes using machine-smoked e-cigarettes and cigarettes $^{10}$.

E-cig's aerosol is a source of high exposure of the human respiratory system to fine particles (100-160 nm); their size and concentration are similar to those of tobacco smoke ${ }^{11}$. Since the composition, inhalation and exposure pattern to e-cig aerosol and tobacco smoke are very different, the health consequences and risks should not be evaluated with the same model.

E-cigs and tobacco cigarettes have similar patterns of particle deposition in the lungs, and nicotine is rapidly absorbed and delivered to the brain. Early pharmacologic reports found that nicotine delivery was significantly slower with e-cigs compared to regular cigarettes, but more recent evidence shows that nicotine levels are influenced by e-cig generation, inhalation patterns, and users' experience ${ }^{1,12}$. In some lategeneration devices, users can increase the heating temperature and therefore, modify the aerosol composition by increasing up to 2.5 -fold the nicotine, formaldehyde, acetaldehyde, and acetone content as well as carbonyl compounds $2,7,12,13$.

Although the toxins' concentration of e-cig's aerosol is significantly lower than that in tobacco cigarette smoke, there is no clinical evidence to support the long-term use so far ${ }^{14-16}$.

\section{EPIDEMIOLOGY}

Epidemiological definition of e-cigarette vapor exposure is challenging since the term user may include from those who use it daily to those who have only used it once or twice $e^{4,17-19}$. Some studies report ecigarette users as ever, regularly or daily users but in any case, the device, filling system, and/or e-liquid used are considered. The heterogeneity and imprecision of this exposure must be taken into consideration as a source of inaccuracy while appraising vaping as a health risk factor.

E-cigarettes were launched in China, in 2003, but they were commercially available in the marketplace in the United States and Europe since $2007^{20}$. Based on a
2014 market report on brands (466), sales (3000 M US\$) and forecast of sales for 2030 to increase by a factor of 17 , the use of e-cigarettes are apparently escalating ${ }^{21}$.

Estimations of e-cigarette use around the world are questionable due to the definition of prevalence. The most reliable data are from International Tobacco Control $(\mathrm{ITC})^{20}$. In a survey to current and former smokers older than 18 years from 10 different countries between 2009 and 2013, 34\% were aware of the e-cigarette, and $4 \%$ had tried it ${ }^{20}$. The authors observed considerable cross-country variation by year of data collection, for awareness (33-88\%), and present use of e-cigarettes $(<1-14 \%)$.

E-cigarette use among young people is a major public health concern globally since it may lead or progress to conventional smoking of cigarettes ${ }^{22,23}$. In Europe, e-cigarette use was associated with younger age and heavier tobacco use. Regular e-cigarette prevalence was also associated with the current (20.3\%), former (4.7\%), and never (1.2\%) tobacco smoker condition ${ }^{24}$. The prevalence of ever, current (at least 1 in the past 30 days), and regular (at least 20 in the past 30 days) e-cigarette use reported in the US, in 2017 , was $7.7 \%, 2.1 \%$, and $0.9 \%$, respectively ${ }^{25}$. Since 2014 , self-report of e-cigarette use among youth exceeded conventional cigarette's consumption ${ }^{1}$.

In Mexico, ENCODAT (National Drugs, Alcohol and Tobacco Use Survey, Encuesta Nacional de Consumo de Drogas, Alcohol y Tabaco) revealed that the prevalence of use of e-cigarettes for 2016-2017 was $0.6 \%$, lower in women $(0.4 \%)$ than in men $(0.9 \%)$. These figures estimate that 5 million persons ever experimented with e-cigarettes, and almost 1 million are regular users ${ }^{26}$. In 2015, 10\% of secondary school students tried e-cigarettes ${ }^{22}$. A 2016 survey among teenagers 11 and 16 years old in Mexico City, Monterrey and Guadalajara revealed a prevalence of having ever experienced e-cig of $35 \%$ and $31 \%$, and regular use, $14 \%$ and $13 \%$, respectively; of them, $5-7 \%$ declared having initiated tobacco smoking after experiencing with e-cigarettes ${ }^{27,28}$.

The characteristics of ever users of e-cigarettes are similar to those reported for conventional cigarettes: male gender, heavier tobacco consumption, family 
and friends smoking tobacco, and tendency for drugseeking ${ }^{22,29}$.

Two waves of the National Adult Tobacco Survey (2012-2013 and 2013-2014) explored characteristics of tobacco quitters and of those who switched to e-cigarettes. Male gender (odds ratio [OR] 1.2; 95\% confidence interval $[\mathrm{Cl}], 1.0-1.5)$ and younger age (18-24 years old; OR $3.6,95 \% \mathrm{Cl} 2.4-5.5$ ) were associated with e-cigarette use before quitting ${ }^{30}$.

Tobacco and e-cigarette consumers declared to use e-cigarettes as an aid to quit smoking ( $52.6 \%$ ), to avoid second-hand tobacco smoke (16.1\%), and also as a harm-reduction tool $(8 \%)^{19,22}$.

Regulation of ENDS varies significantly between countries, and to date, there is no consensus among the ITC community ${ }^{20}$. While in the UK there are few restrictions and ENDS is widely available, the US Food and Drug Administration (FDA) proposed regulations similar to those for traditional tobacco products, and FCTC's COP recommended objective-based regulations (prevent initiation in non-smokers and youth, reduce ENDS' health risks and second-hand emissions, prevent unproven health claims, protect tobacco control activities, avoid commercial interests, in particular, and of tobacco industry) ${ }^{31}$.

\section{THE HEALTH RISK DILEMMA OF E-CIGARETTES}

Since Doll's report, in 1954, uncontroversial evidence has been growing regarding the burden of health consequences of smoking tobacco. However, a global health response consistent with the magnitude of the challenge was launched only half a century lat$\mathrm{er}^{32}$. Along the XXI century, the world will still be facing hundreds of millions of deaths as a toll of nicotine addiction and tobacco industry revenues. The tobacco documents released in 1998 as a response to a legal action revealed the ignominious and systematic efforts of these cartels to prevent the decline of their trade ${ }^{33}$. In fact, one of the strategies of tobacco manufacturers in the 60 s was to launch light and low-tar cigarettes as less harmful smoking. Subsequent studies not only failed to demonstrate the health benefits of smoking light and low-tar cigarettes versus standard cigarettes but also they observed an increase in the risk as well ${ }^{1,34}$.

Faced with the categorical evidence of the burden of tobacco deaths, the tobacco industry developed a broad and comprehensive strategy to preserve and expand their market. Creating doubt and controversy around the health risks of tobacco, and promoting falsely safer smoking products were cornerstones of this strategy. During the $70 \mathrm{~s}$ and $80 \mathrm{~s}$, filtered or "light" and "low" tar or "low" nicotine cigarettes created among smokers a wrong impression of being less harmful than others, which may have curbed their motivation to quit smoking. The WHO Framework Convention on Tobacco Control Art 11 addressed and promoted parties to regulate tobacco product packaging and labeling to avoid by any means false, misleading, and deceptive messages ${ }^{32}$.

E-cigarette is now reloading the dilemma of low-risk nicotine consumption through the respiratory system. The cornerstone argument of e-cigarette supporters is that the vapor's concentration of toxic substances is significantly lower than that of tobacco smoke ${ }^{35-37}$.

By modeling analysis, a selected number of drug experts estimated the harm of nicotine products, concluding that e-cigarette's relative harm is $5 \%$ compared to cigarettes. Some limitations to this argument should also be addressed apart from the conflict of interest warned by journals' editors. First, there is a clear inductive fallacy in the paper by Nutt et al., since harm reduction was estimated based on the authors' opinion while they recognized the lack of hard evidence for the harm of most of the nicotine products $^{35}$. Second, the process for recruiting experts was not specified, resulting in potentially serious selection bias. Finally, asking the experts to assign a scale value based on their subjective perception of harm for each product, and the difference in damage between the most and least harmful products in 16 dimensions, leads to several criticisms, as has been observed $^{38}$.

This paper was the pillar for the Public Health England e-cigarette report, translated into two questionable statements: "e-cigs are $95 \%$ safer than smoking" and "tobacco health burden can be reduced by $95 \%$ if all smokers move to e-cigarettes" 39 . 


\section{MECHANISMS OF DAMAGE OF E-CIGARETTES}

There is no doubt that the concentration of ingredients in e-cigarettes' aerosol is significantly lower than that of combustible cigarettes, but this does not mean that it is "harmless vapor." As described, ecigarettes are a novel source of high concentrations of submicron-sized particles, and users are subjected to an unusual and original model of inhalation exposure since the inhalation pattern of e-cigarettes in terms of length, volume, and puffing frequency is different from that of conventional cigarettes. The aerosol generated "in vitro" has particle sizes in the range of 100-600 nm, similar to the conventional cigarettes. Other studies described a bimodal particle size distribution: 11-25 $\mathrm{nm}$ and $\mathrm{p}$ 96-175 $\mathrm{nm}^{11}$. One report estimated that $6.25 \times 10^{10}$ particles generated would be deposited in the respiratory system while most particle depositions would occur in the alveolar region $^{2}$. Ultrafine particles, $<100 \mathrm{~nm}$, were described to cause DNA damage, pro-inflammatory cytokine expression and production of free oxygen radicals ${ }^{11}$.

Among the aerosol's contents described above, potent carcinogens such as NNN and NNK were identified in the vapors generated from a different brand of e-cigarettes ${ }^{40}$. TSNAs are related to curing and processing tobacco, or possibly with the addition of tobacco flavorings $s^{1,41}$. Formaldehyde, acetaldehyde, and acrolein are well-known potent irritants and toxics and have been found exceeding the National Institute of Occupational Safety and Health recommended level for short-term exposure ${ }^{6}$. There is also growing concern for the presence of heavy metals in e-liquids as potential carcinogens ${ }^{42}$.

Flavoring components of e-cigarettes are major contributors of carbonyl species production ${ }^{2}$. In one report, diacetyl (DA, the most well-known artificial flavoring) and acetyl propionyl were found in $28.3 \%$ of a sample of e-liquids. These substances were associated with bronchiolitis obliterans that cause fixed obstructive lung disease ${ }^{1}$. Nicotine concentrations in the e-cigarette vapor vary more widely than in conventional cigarette's smoke ${ }^{1}$. Most e-liquids, even those labeled as "nicotine free," contain nicotine and 60$70 \%$ of the nicotine is the one released by the aerosol ${ }^{9,13}$. E-liquid labels report the nicotine concentration, but this is inaccurate. Goniewicz et al. estimated an average of $82.8 \mathrm{mg}$ of nicotine per $100 \mathrm{~mL}$ of aerosol in an 18-mg nicotine cartridge, and in those e-cigarettes in which 15 puffs are equivalent to smoking one cigarette ${ }^{41}$. A typical cigarette delivers approximately $2 \mathrm{mg}$ of nicotine to its smoker, and the lethal dose $L D_{50}$ is $60 \mathrm{mg}^{2}$. The evidence supports that nicotine availability in e-cigarettes is effective to saturate brain receptors and to avoid abstinence symptoms ${ }^{43,44}$.

The systemic and airways' changes observed after exposure to e-cigarette aerosol may be explained by different mechanisms, some of which are still under debate and research:

Aldehydes (formaldehyde and acrolein) exposure has been associated with altered epithelial response, mucus hypersecretion, activation, and degranulation of neutrophils and induction of neutrophil apoptosis ${ }^{12}$.

Exposures to e-cig aerosol induce measurable oxidative and inflammatory responses in lung cells and tissues, and in bronchial epithelial cells cause acute toxicity and reduce the antiviral response ${ }^{45,46}$. E-cigarette users show increased proteins secretion in sputum related to the innate defense functions of leukocytes, bronchial inflammation, and structural damage. These include neutrophil elastase, proteinase 3 , azurocidin 1 , and myeoloperoxidase as well as other secondary neutrophil granule proteins ${ }^{12}$.

Exposure to e-cigarette induces platelet aggregation and upregulates expression of CD41, CD42b, and CD62p, independently of nicotine content and exposure time possibly due to fine particulate matter. These facts may be the hallmarks of cardiovascular and other systemic diseases ${ }^{47}$.

E-cigarettes have been linked to lung and systemic damage (Table 1), with consistent evidence and biologic plausibility that the constituents of e-cigarettes' aerosol cause airway irritation, bronchitis, cough, phlegm, bronchoconstriction, platelet dysfunction, and carcinogenic changes among others (Fig. 2).

\section{IN VITRO DAMAGE BY E-CIGARETTES AND EVIDENCE IN ANIMAL MODELS}

There is emerging evidence of possible pathways and toxicities of e-cig aerosols, but there are still many 
Table 1. Components of e-cigarettes and potential damage.

\begin{tabular}{|c|c|c|}
\hline & Components & Potential damage \\
\hline Metal material & $\begin{array}{l}\text { Batteries and heating element: nichrome wire } \\
\text { ( } 80 \% \text { nickel, } 20 \% \text { chrome), kanthal, iron, } \\
\text { chromium, aluminum, ceramic, silica. }\end{array}$ & $\begin{array}{l}\text { Carcinogen, respiratory, and reproductive toxicant; } \\
\text { respiratory disease and autoimmune dysfunction. }\end{array}$ \\
\hline \multirow[t]{3}{*}{ E-liquids } & Nicotine & $\begin{array}{l}\text { Concentrations range from } 0 \text { to } 50 \mathrm{mg} / \mathrm{mL} \text {. } \\
\text { Impair antibacterial defense, alter macrophage } \\
\text { activation. }\end{array}$ \\
\hline & $\begin{array}{l}\text { Pyrolysis of blanks: one or mixture solvent } \\
\text { (PG or VG) }\end{array}$ & $\begin{array}{l}\text { Mixture PG/VG produced more ROS than either } \\
\text { alone resulting in inflammation, cytotoxicity, and } \\
\text { increased endothelial cell permeability. }\end{array}$ \\
\hline & $\begin{array}{l}\text { Flavorings (tobacco, menthol, candy, beverage } \\
\text { themed) }\end{array}$ & $\begin{array}{l}\text { "Primary irritants" } \\
\text { Cinnamon increases cytokine IL-8 } \\
\text { Diacetyl: bronchiolitis obliterans } \\
\text { Not all have been tested for safety when inhaled. }\end{array}$ \\
\hline \multirow[t]{6}{*}{ Aerosol } & TSNAs, NNN & Potent carcinogens \\
\hline & Acrolein & Increase risk of lung cancer, asthma, COPD. \\
\hline & Glycidol & Probable carcinogen \\
\hline & Formaldehyde & Epithelial response and increasing mucin secretion \\
\hline & VOCs & Irritation, headaches, organ damage \\
\hline & PAHs & Carcinogens \\
\hline
\end{tabular}

PG: propylene glycol, VG: vegetable glycerin, ROS: reactive oxygen species, TSNAs: tobacco-specific nitrosamines, NNN: N-nitrosonornicotine, COPD: chronic obstructive pulmonary disease, VOCs: volatile organic compounds, PAHs: polycyclic aromatic hydrocarbons.

important gaps to understand fully the burden of harms from this distinctive and varied exposure ${ }^{2}$. In vitro exposure of human bronchial cells to e-cigarettes' carrier solution containing PG and/or VG decreased cell metabolic activity, bronchial cell viability and cilia activity, and increased mitochondrial oxidative stress (consistent with reduced glutathione levels) $)^{2,13}$. Some reports suggest that artificial flavoring and nicotine concentrations may influence these dysfunctions ${ }^{45,48-50}$. In vivo, short-term exposure to ecigarette aerosols in mice models reproduced similar changes resulting in oxidative stress, macrophagemediated inflammation, and lung injury with increased capillary permeability ${ }^{45,51}$. Furthermore, exposure to e-cigarette aerosol in mice showed impaired bacterial and influenza A clearance, increase in lung viral titers, and deleterious effects in morbidity and mortality ${ }^{51}$. Other report highlighted the increase of bacterial load, especially of methicillin-resistant Staphylococcus aureus, pneumococcal adhesion to upper and lower airway epithelial cells, and increased macrophages in bronchoalveolar lavage samples, but with impaired bacterial phagocytosis and increased alveolar-capillary permeability ${ }^{2,52}$.
One report explored long-term exposure to e-cigarette aerosol containing nicotine in a mouse model and human bronchial epithelial cells and revealed changes as a causative factor of progression of chronic obstructive pulmonary disease (COPD), including cytokine expression, airway hyperreactivity, and lung tissue destruction ${ }^{53}$.

\section{SYSTEMIC IMPACT OF E-CIGARETTES IN HUMANS}

Nicotine induces stimulation of the sympathetic nervous system, with tachycardia, increase in blood pressure and cardiac output, leading to an increase in myocardial oxygen consumption as well as vasoconstriction of cutaneous and coronary blood vessels ${ }^{54}$. Increased cardiac sympathetic activity associated to regular smoking was described 20 years ago and, lately, similar effects were observed for e-cigarette as well as oxidative stress and inflammation signaling ${ }^{55-57}$. Recently, evidence of population-based e-cigarette impact on cardiovascular health has been reported ${ }^{56,57}$. 
Figure 2. Probable mechanisms of lung abnormalities with e-cigarette. The combination between high temperature and several components of e-aerosol including particulate matter (1) has the potential of generating pro-inflammatory effects, production of reactive oxygen species in lung with varied consequences such as airway hyperreactivity, increased airway resistance, decreased antimicrobial activity, decreased alveolar development, endothelial disruption, and fragmentation of fibroblasts (2). Systemic changes are produced by nicotine with increases in heart rate and blood pressure, as well as an addiction with all consequences including tolerance, craving, abstinence, and change to normal cigarettes or inhalation of other liquids containing other drugs (3).

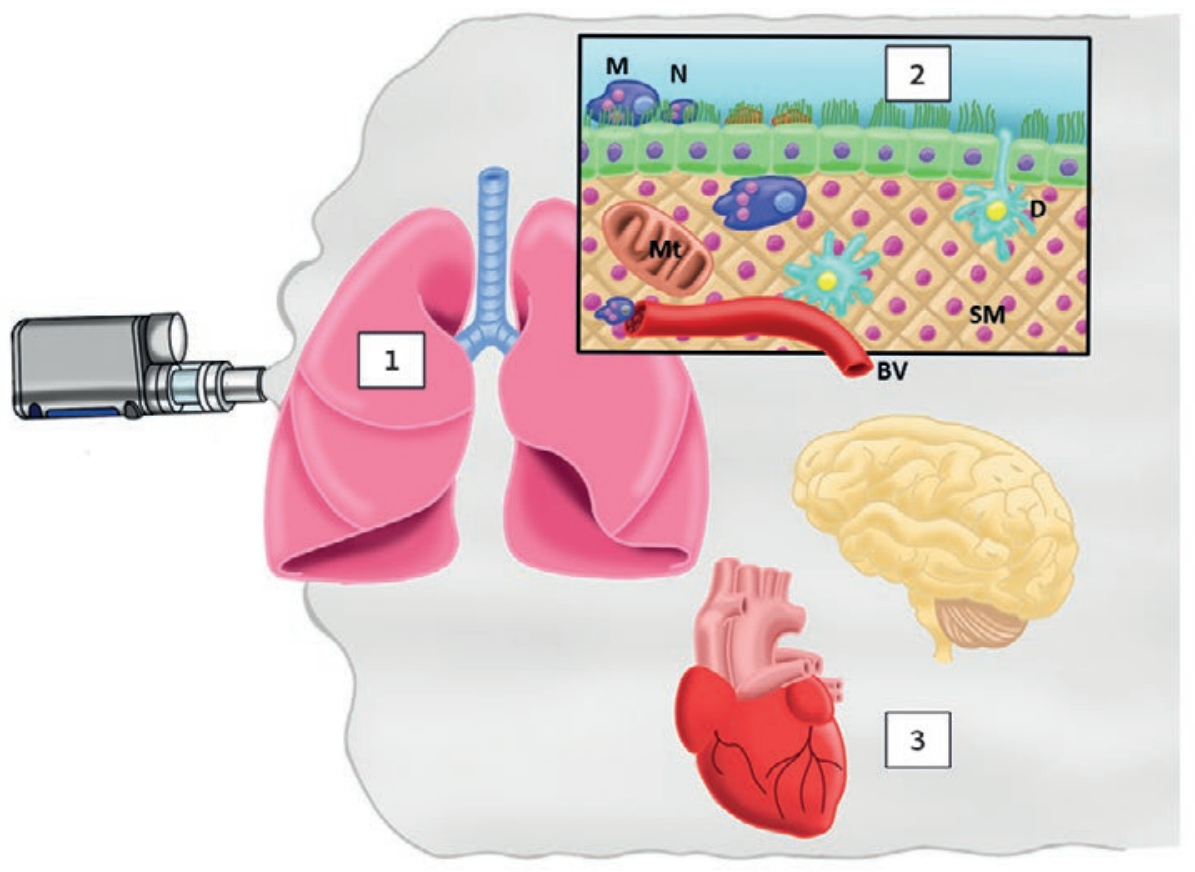

M: macrophage, N: neutrophils, D: dendritic cell, BV: blood vessel, SM: smooth muscle, Mt: mitochondria.

There is considerable evidence that carcinogenic substances and some compounds causing DNA damage and mutagenesis have been detected in e-cigarette aerosols, but there is no available evidence so far that e-cigarette use is associated with cancer, abnormal fetal development, or immune defects leading to increased risk of respiratory infections ${ }^{18}$. However, the period of observation since the massive launch of ecigarettes is too short to analyze the occurrence of cancer. On the other hand, there is usually a time gap between the description of toxicologic impacts on in vitro or in vivo models and the description of clinical or epidemiologic outcomes. The diversity of the devices and exposures is also barriers to categorize the exposure ${ }^{18}$.

Other reported risks associated with e-cigarette use include device explosions, accidental, and intentional poisoning with PG and nicotine overdose in children, increased circulating endothelial progenitor cells, and potential acute endothelial injury, and nickel contact dermatitis ${ }^{2,18}$.

\section{EVIDENCE OF PULMONARY DAMAGE ASSOCIATED WITH E-CIGARETTE EXPOSURE IN HUMANS}

While evidence of median and long-term adverse effects of e-cigarette exposure on the respiratory system emerges, it is desirable to review and monitor intermediate outcomes, such as alterations in lung structure and function and respiratory symptoms ${ }^{18}$. Most of the information comes from dual users (smoking tobacco and e-cigs) or individuals switching completely from conventional tobacco smoking to ecigarettes, thus avoiding a valid comparison of users of e-cigs versus unexposed individuals ${ }^{2,58,59}$. Studies 
in healthy e-cigarette users revealed an increase in oxidative stress, nitric oxide deficiency, and endothelial/vascular dysfunction; acute and short-time exposure to PG in aerosol from artificial smoke generators resulted in ocular and respiratory symptoms and deleterious lung function in healthy non-asthmatic patients, but this evidence, in contrast with the effect of tobacco smoke, is considered marginal ${ }^{13,60,61}$.

Exposure to e-cigarette aerosol has been associated with respiratory symptoms in healthy individuals, changes in respiratory physiology and host defense, and with increased symptoms in asthma, cystic fibrosis (CF), and COPD².

There is growing evidence that adolescents who were exposed to e-cigarettes more often have cough and phlegm (OR 2.1, 95\% Cl 1.8-2.5) 62,63 . Adolescents using e-cigarettes more frequently report not only respiratory symptoms but also school absenteeism ${ }^{18,64}$. Airway exposure to nicotine-containing ecigarette vapor inhibits bronchial and nasal mucociliary clearance, with the production of a cough and rhino-nasal symptoms, compared with individuals unexposed to e-cigarette aerosol ${ }^{18,65}$.

Short-term exposure to e-cigarette with and without nicotine in healthy adults increases airway resistance and reduces nitric oxide in exhaled air (fractional exhaled nitric oxide, FeNO) ${ }^{1,18,66}$. This evidence is consistent with a report that revealed decreased pulmonary function (decrease in forced expiratory volume in one second $\left[\mathrm{FEV}_{1}\right], \mathrm{FEV}_{1} /$ forced vital capacity; and increase in airflow resistance) after exposure to aerosolized PG in healthy humans ${ }^{2,10,66}$. So far, there is neither evidence supporting long-term safety nor improvements in lung function in smokers who switch to e-cigarettes, as is observed in quitters ${ }^{67}$.

Recent evidence reports parenchymal and bronchial inflammation, lung damage and toxicity (e.g., lipoid pneumonia), as well as impaired systemic inflammation signaling, and defense mechanisms associated with e-cigarette exposure ${ }^{12,58}$.

\section{E-CIGARETTE AND MORE COMMON LUNG DISEASES}

A recent report revealed that the prevalence of ever use of e-cigarettes was higher among adults with one or more comorbidities, compared with those without comorbidities, and in smokers with COPD, asthma, and cardiovascular disease compared to "healthy" smokers ${ }^{68}$. Use of e-cigarette was associated with higher odds of asthma symptoms, considering cigarette smoking and marijuana use ${ }^{69}$. Adolescents with asthma or CF who use e-cigarettes were more likely to have respiratory symptoms and exacerbations ${ }^{18,64}$. Common flavoring agents in e-cigarettes are recognized as "primary irritants" of mucosal tissue of the respiratory tract; airway irritants and sensitizers have been reported to cause occupational asthma ${ }^{64}$.

In patients with COPD, the use of e-cigarettes has been associated with more cough and phlegm, more exacerbations and possibly a more rapid decline in lung function, even after adjusting for tobacco smoking and age ${ }^{70}$.

E-cigarettes have been shown to lower indoor air quality, and non-smokers have been found to absorb nicotine from second-hand vaping comparable to passive smoking 2,9 . Although passive exposure to e-cigarette vaping does not include combustion of toxic agents, there is significant secondhand exposure to nicotine in the exposure chamber, leading to serum cotinine levels among those exposed that can be higher than levels obtained from conventional cigarettes ${ }^{9}$.

\section{SMOKING CESSATION WITH E-CIGARETTES}

Two Cochrane reviews had explored in 2014 and 2016 the effectiveness of e-cigarettes for smoking cessation and safety, and both agreed on the low quality of the evidence based only on a small number of studies; therefore, further research was suggested $^{71-75}$. The latter meta-analysis revealed that abstinence was higher among e-cigarette users compared with placebo, but no effect was observed comparing e-cigarettes with nicotine patches. Despite the scarce information, supporters of e-cigarettes promote them as a better option to smoking or to reduce cigarette consumption in a harm-reduction strategy, while skeptic tobacco-control actors alert of a boost in the nicotine market by attracting youths that may later start smoking regular cigarettes ${ }^{73,76,77}$.

In fact, a major public health concern is e-cigarettes arising as a novel, high-tech pathway to nicotine 
addiction through early experimentation by children and adolescents, since e-cigarettes saturate the nicotinic receptors in the brain as much as conventional cigarettes do $\mathrm{do}^{28,69,78}$.

Recent "aggressive" and restriction-free e-cigarette advertisements in internet sites, social media and movies resulted in a growing awareness, perception of safer behavior than smoking, and increased appeal and interest to try e-cigarettes ${ }^{79,80}$. Data from the US, Canada, United Kingdom, and Australia obtained in the ITC project revealed a higher prevalence of ecigarette use among young and non-daily smokers, as a consequence of feeling that vaping was safe. However, teens and young adults from the US who have used e-cigarettes were in a significantly higher risk of smoking regular cigarettes in the following years (OR $3.87 ; 95 \% \mathrm{Cl}, 1.86-8.06$ ), a risk also found in a new longitudinal study in Great Britain (OR 1.34; $95 \% \mathrm{Cl}$, 1.05-1.72; $p=0.018)^{29,78,81}$. A recent meta-analysis confirmed that e-cigarette experimentation among never smokers almost quadrupled the chances of becoming a smoker at follow-up ${ }^{82}$.

Flavoring or taste in e-cigarette not only stimulated experimentation and initiation behaviors but also increased the risk of smoking combustible cigarettes $^{83,84}$. These facts may partially explain the dramatic increase in e-cigarette use among youths observed in the US, UK, Italy, Poland, South Korea and Finland, and among other countries.

A key public health challenge is e-cigarette initiation in a never-smoker youth, as it may not only cause harm to the respiratory system but also lead to smoke regular cigarettes and vape other substances, like cannabis derivatives.

The awareness of e-cigarettes' potential health risk, their regulation as tobacco products, and the promotion of banning must be considered among other actions to prevent the evolving scenario ${ }^{3,18}$. In the US, FDA e-cigarette policies resulted in a significant decline of e-cigarette use among young persons, in $2016^{85}$.

In established smokers, an e-cigarette may be less deleterious to the respiratory system, but so far there is insufficient evidence of whether e-cigarettes increase the likelihood of smoking cessation ${ }^{19}$.
Furthermore, existing reports fail to compare e-cigarettes with state-of-the-art proven therapies.

\section{CONCLUSION}

For $>50$ years, a solid body of incontrovertible evidence revealed that smoking cigarettes are a cause of disease in almost every organ of the body ${ }^{1}$. In the early 60 s, it was a challenge to prove the real burden of tobacco on global health, as the evidence required decades to emerge entirely; in the meantime, millions of deaths occurred. Now, e-cigarettes emerged, spread promptly, and challenge the scientific, and public health community, since they have to act to control and regulate the market based on public health, even with incomplete proofs and evidence, which are needed without delay 7,86 .

ENDS, and particularly e-cigarettes, are devices that effectively deposit nicotine in the brain and generate nicotine addiction. These e-cigarette aerosols contain fewer toxins than tobacco smoke, but a safety comparator must be clean air breathing. There is growing evidence of the presence of a variety of toxic products in vaporizing liquids in e-cigarettes that result in chemical, morphologic, and functional deleterious effects in in vitro and in vivo models ${ }^{12,47}$. Evidence for acute respiratory damage and toxicity is evolving, but data on mid- and long-term effects are still lacking as well as standardization models to compare different devices.

It is urgent to regulate e-cigarette design, e-liquid and aerosol composition, health warnings, marketing, promotion, sales, taxation, and secondhand vapor exposure at least at a level equivalent to that of regular tobacco products 22,78 .

\section{REFERENCES}

1. Disease Control Center for Chronic Disease Prevention, Promotion on Smoking. E-Cigarette use among Youth and Young Adults: A Report of the Surgeon General. Rockville, MD: Department of Health Services for Disease; 2016

2. Chun LF, Moazed F, Calfee CS, Matthay MA, Gotts JE. Pulmonary toxicity of e-cigarettes. Am J Physiol Lung Cell Mol Physiol. 2017;313:L193-206

3. Monraz-Pérez S, Regalado-Pineda J, Pérez-Padilla R. El cigarro electrónico: peligro u oportunidad. Neumol Cir Torax. 2015; 74:82-6

4. Kalkhoran S, Glantz SA. E-cigarettes and smoking cessation in real-world and clinical settings: a systematic review and metaanalysis. Lancet Respir Med. 2016;4:116-28 
5. Barbara D. A high-tech Approach to Getting a Nicotine Fix. The Electronic Cigarette-a Gadget that looks like the Real Thing and Delivers Nicotine Without Smoke-is Established in China, and Companies are Taking aim at the U.S. market. Los Angeles Times; 2009

6. Herrington JS, Myers C. Electronic cigarette solutions and resultant aerosol profiles. J Chromatogr A. 2015;1418:192-9

7. Breland A, Soule E, Lopez A, et al. Electronic cigarettes: what are they and what do they do? Ann N Y Acad Sci. 2017;1394:5-30

8. Williams M, Villarreal A, Bozhilov K, Lin S, Talbot P. Metal and silicate particles including nanoparticles are present in electronic cigarette cartomizer fluid and aerosol. PLoS One. 2013; 8:e57987

9. Czogala J, Goniewicz ML, Fidelus B, et al. Secondhand exposure to vapors from electronic cigarettes. Nicotine Tob Res. 2014; 16:655-62

10. Flouris AD, Chorti MS, Poulianiti KP, et al. Acute impact of active and passive electronic cigarette smoking on serum cotinine and lung function. Inhal Toxicol. 2013;25:91-101

11. Zhang Y, Sumner W, Chen DR. In vitro particle size distributions in electronic and conventional cigarette aerosols suggest comparable deposition patterns. Nicotine Tob Res. 2013;15:501-8

12. Reidel B, Radicioni G, Clapp PW, et al. E-cigarette use causes a unique innate immune response in the lung, involving increased neutrophilic activation and altered mucin secretion. Am J Respir Crit Care Med. 2018;197:492-501

13. Cai $H$, Wang C. Graphical review: the redox dark side of e-cigarettes; exposure to oxidants and public health concerns. Redox Biol. 2017;13:402-6

14. Callahan-Lyon P. Electronic cigarettes: human health effects. Tob Control. 2014;23 Suppl 2:ii36-40

15. Dinakar C, O'Connor GT. The health effects of electronic cigarettes. N Engl J Med. 2016;375:1372-81

16. Schraufnagel DE, Blasi F, Drummond MB, et al. Electronic cigarettes. A position statement of the forum of international respiratory societies. Am J Respir Crit Care Med. 2014;190:611-8

17. Amato MS, Boyle RG, Levy D. How to define e-cigarette prevalence? Finding clues in the use frequency distribution. Tob Control. 2016:25:e24-9

18. Stratton K, Kwan LY, Eaton DL. Committee on the Review of the Health Effects of Electronic Nicotine Delivery Systems, Board on Population Health and Public Health Practice, Health and Medicine Division, National Academies of Sciences, Engineering, and Medicine. Public Health Consequences of E-Cigarettes. Washington, D.C. National Academies Press; 2018

19. Biener L, Hargraves JL. A longitudinal study of electronic cigarette use among a population-based sample of adult smokers: association with smoking cessation and motivation to quit. Nicotine Tob Res. 2015;17:127-33

20. Gravely S, Fong GT, Cummings KM, et al. Awareness, trial, and current use of electronic cigarettes in 10 countries: findings from the ITC project. Int J Environ Res Public Health. 2014; 11:11691-704

21. Conference of the Parties to the WHO Framework Convention on Tobacco Control. Electronic nicotine delivery systems. FCTC/ COP/6/10 Rev.1; 2014

22. Thrasher JF, Abad-Vivero EN, Barrientos-Gutíerrez I, et al. Prevalence and correlates of E-cigarette perceptions and trial among early adolescents in Mexico. J Adolesc Health. 2016:58:358-65

23. Lozano P, Barrientos-Gutierrez I, Arillo-Santillan E, et al. A longitudinal study of electronic cigarette use and onset of conventional cigarette smoking and marijuana use among Mexican adolescents. Drug Alcohol Depend. 2017:180:427-30

24. Vardavas CI, Filippidis FT, Agaku IT. Determinants and prevalence of e-cigarette use throughout the European Union: a secondary analysis of $26 / 566$ youth and adults from 27 countries. Tob Control. 2015:24:442-8

25. Levy DT, Yuan Z, Li Y. The prevalence and characteristics of Ecigarette users in the U.S. Int J Environ Res Public Health. 2017;14:10

26. Secretaría de Salud. ENCODAT Encuesta Nacional de Consumo de Drogas, Alcohol y Tabaco 2016-2017 Reporte de Tabaco; 2017

27. Instituto Nacional de Salud Pública. Consumo de Nicotina en Alumnos de Secundaria, 2016. Tabaco y cine en América Latina. México: Instituto Nacional de Salud Pública; 2016

28. Instituto Nacional de Salud Pública. Consumo de Substancias en Alumnos de Secundaria, 2015-2016. Tabaco y cine en América Latina. México: INSP; 2016

29. East K, Hitchman SC, Bakolis I, et al. The association between smoking and electronic cigarette use in a cohort of young people. J Adolesc Health. 2018;62:539-47
30. Park SH, Duncan DT, Shahawy OE, et al. Characteristics of adults who switched from cigarette smoking to E-cigarettes. Am J Prev Med. 2017;53:652-60

31. David K. The Deeming Rule: Vape Shops. Division of Enforcement and Manufacturing Office of Compliance and Enforcement, CTP, FDA; 2016

32. World Health Organization. WHO Framework Convention on Tobacco Control. Geneva: World Health Organization; 2003

33. World Health Organization. The Tobacco Industry Documents What they are, What They Tell us, and How to Search Them. A Practical Manual. Geneva, Switzerland: World Health Organization; 2004

34. U.S Department of Health and Human Services Food and Drug Administration Center for Tobacco Products. Guidance for Industry and FDA Staff. Use of Light, Mild, Low, or Similar Descriptors in the Label, Labeling, or Advertising of Tobacco Products. U.S Department of Health and Human Services Food and Drug Administration Center for Tobacco Products: 2010

35. Nutt DJ, Phillips LD, Balfour D, et al. Estimating the harms of nicotine-containing products using the MCDA approach. Eur Addict Res. 2014:20:218-25

36. Hajek P, Etter JF, Benowitz N, Eissenberg T, McRobbie H. Electronic cigarettes: review of use, content, safety, effects on smokers and potential for harm and benefit. Addiction. 2014 109:1801-10

37. Farsalinos KE, Polosa R. Safety evaluation and risk assessment of electronic cigarettes as tobacco cigarette substitutes: a systematic review. Ther Adv Drug Saf. 2014:5:67-86

38. Polosa R. E-cigarettes: public health England's evidence based confusion? Lancet. 2015;386:1237-8

39. McNeill A, Brose LS, Calder R, Hitchman SC. E-cigarettes: An Evidence Update. London: A Report Commissioned by Public Health England; 2015

40. Goniewicz ML, Knysak J, Gawron M, et al. Levels of selected carcinogens and toxicants in vapour from electronic cigarettes. Tob Control. 2014:23:133-9

41. Goniewicz ML, Kuma T, Gawron M, Knysak J, Kosmider L. Nicotine levels in electronic cigarettes. Nicotine Tob Res. 2013 15:158-66

42. Hess CA, Olmedo P, Navas-Acien A, et al. E-cigarettes as a source of toxic and potentially carcinogenic metals. Environ Res. 2017:152:221-5

43. Vansickel AR, Weaver MF, Eissenberg T. Clinical laboratory assessment of the abuse liability of an electronic cigarette. Addiction. 2012;107:1493-500

44. Farsalinos KE, Spyrou A, Tsimopoulou K, et al. Nicotine absorption from electronic cigarette use: comparison between first and new-generation devices. Sci Rep. 2014;4:4133

45. Lerner $\mathrm{CA}$, Sundar IK Yao $\mathrm{H}$ et al. Vapors produced by electronic cigarettes and e-juices with flavorings induce toxicity oxidative stress, and inflammatory response in lung epithelial cells and in mouse lung. PLoS One. 2015;10:e0116732

46. Higham A, Bostock D, Booth G, Dungwa JV, Singh D. The effect of electronic cigarette and tobacco smoke exposure on COPD bronchial epithelial cell inflammatory responses. Int J Chron Obstruct Pulmon Dis. 2018:13:989-1000

47. Hom S, Chen L, Wang T, et al. Platelet activation, adhesion, inflammation, and aggregation potential are altered in the presence of electronic cigarette extracts of variable nicotine concentrations. Platelets. 2016:27:694-702

48. Leigh NJ, Lawton RI, Hershberger PA, Goniewicz ML. Flavourings significantly affect inhalation toxicity of aerosol generated from electronic nicotine delivery systems (ENDS). Tob Control. 2016; 25:ii81-7

49. Scheffler S, Dieken H, Krischenowski O, et al. Evaluation of Ecigarette liquid vapor and mainstream cigarette smoke after direct exposure of primary human bronchial epithelial cells. Int J Environ Res Public Health. 2015;12:3915-25

50. Schweitzer KS, Chen SX, Law S, et al. Endothelial disruptive proinflammatory effects of nicotine and e-cigarette vapor exposures. Am J Physiol Lung Cell Mol Physiol. 2015;309:L175-87

51. Sussan TE, Gajghate S, Thimmulappa RK, et al. Exposure to electronic cigarettes impairs pulmonary anti-bacterial and anti-viral defenses in a mouse model. PLoS One. 2015 10:e0116861

52. Miyashita L, Suri R, Dearing E, et al. E-cigarette vapour enhances pneumococcal adherence to airway epithelial cells. Eur Respir J. 2018;51:1-10.

53. Garcia-Arcos I, Geraghty P, Baumlin N, et al. Chronic electronic cigarette exposure in mice induces features of COPD in a nicotine-dependent manner. Thorax. 2016;71:1119-29 
54. Benowitz NL. Pharmacology of nicotine: addiction, smoking-induced disease, and therapeutics. Annu Rev Pharmacol Toxicol. 2009;49:57-71

55. Narkiewicz K, van de Borne PJ, Hausberg M, et al. Cigarette smoking increases sympathetic outflow in humans. Circulation. 1998;98:528-34

56. Moheimani RS, Bhetraratana M, Yin F, et al Increased cardiac sympathetic activity and oxidative stress in habitual electronic cigarette users: implications for cardiovascular risk. JAMA Cardiol. 2017;2:278-84

57. Qasim H, Karim ZA, Rivera JO, Khasawneh FT, Alshbool FZ. Impact of electronic cigarettes on the cardiovascular system. J Am Heart Assoc. 2017;6:1-14.

58. Shields PG, Berman M, Brasky TM, et al. A review of pulmonary toxicity of electronic cigarettes in the context of smoking: a focus on inflammation. Cancer Epidemiol Biomarkers Prev. 2017;26:1175-91

59. Polosa R, Cibella F, Caponnetto $P$, et al. Health impact of Ecigarettes: a prospective 3.5-year study of regular daily users who have never smoked. Sci Rep. 2017;7:13825

60. Wieslander G, Norbäck D, Lindgren T. Experimental exposure to propylene glycol mist in aviation emergency training: acute ocular and respiratory effects. Occup Environ Med. 2001; 58:649-55

61. Polosa R, Russell C, Nitzkin J, Farsalinos KE. A critique of the US surgeon general's conclusions regarding e-cigarette use among youth and young adults in the United States of America. Harm Reduct J. 2017;14:61

62. McConnell R, Barrington-Trimis JL, Wang K, et al. Electronic cigarette use and respiratory symptoms in adolescents. Am J Respir Crit Care Med. 2017;195:1043-9

63. Cho JH, Paik SY. Association between electronic cigarette use and asthma among high school students in South Korea. PLoS One. 2016;11:e0151022

64. Clapp PW, Jaspers I. Electronic cigarettes: their constituents and potential links to asthma. Curr Allergy Asthma Rep. 2017;17:79

65. Kumral TL, Saltürk Z, Yildirim G, et al. How does electronic cigarette smoking affect sinonasal symptoms and nasal mucociliary clearance? B-ENT. 2016;12:17-21

66. Vardavas $\mathrm{Cl}$, Anagnostopoulos N, Kougias M, et al. Short-term pulmonary effects of using an electronic cigarette: impact on respiratory flow resistance, impedance, and exhaled nitric oxide. Chest. 2012;141:1400-6

67. Anthonisen NR, Connett JE, Murray RP. Smoking and lung function of lung health study participants after 11 years. Am J Respir Crit Care Med. 2002;166:675-9

68. Kruse GR, Kalkhoran S, Rigotti NA. Use of electronic cigarettes among U.S. Adults with medical comorbidities. Am J Prev Med. 2017:52:798-804

69. Schweitzer RJ, Wills TA, Tam E, Pagano I, Choi K. E-cigarette use and asthma in a multiethnic sample of adolescents. Prev Med. 2017;105:226-31

70. Bowler RP, Hansel NN, Jacobson S, et al. Electronic cigarette use in US adults at risk for or with COPD: analysis from two observational cohorts. J Gen Intern Med. 2017;32:1315-22
71. McRobbie H, Bullen C, Hartmann-Boyce J, Hajek P. Electronic cigarettes for smoking cessation and reduction. Cochrane Database Syst Rev. 2014;1-58:CD010216

72. Caponnetto P, Campagna D, Cibella F, et al. Efficiency and safety of an electronic cigarette (ECLAT) as tobacco cigarettes substitute: a prospective 12-month randomized control design study. PLoS One. 2013;8:e66317

73. Polosa R, Caponnetto P, Morjaria JB, et al. Effect of an electronic nicotine delivery device (e-cigarette) on smoking reduction and cessation: a prospective 6-month pilot study. BMC Public Health. 2011;11:786

74. Bullen C, Howe C, Laugesen M, et al. Electronic cigarettes for smoking cessation: a randomised controlled trial. Lancet. 2013 382:1629-37

75. Hartmann-Boyce J, McRobbie H, Bullen C, et al. Electronic cigarettes for smoking cessation. Cochrane Database Syst Rev. 2016;9:CD010216

76. Gulland A. E-cigarettes help smokers quit, cochrane review confirms. BMJ. 2016;354:i4993

77. Glantz SA, Bareham DW. E-cigarettes: use, effects on smoking, risks, and policy implications. Annu Rev Public Health. 2018. 39:215-35

78. Primack BA, Soneji S, Stoolmiller M, Fine MJ, Sargent JD. Progression to traditional cigarette smoking after electronic cigarette use among US adolescents and young adults. JAMA Pediatr. 2015;169:1018-23

79. Singh T, Agaku IT, Arrazola RA, et al. Exposure to advertisements and electronic cigarette use among US middle and high school students. Pediatrics. 2016;137:1-7.

80. Vasiljevic M, Petrescu DC, Marteau TM. Impact of advertisements promoting candy-like flavoured e-cigarettes on appeal of tobacco smoking among children: an experimental study. Tob Control. 2016;25:e107-12

81. Bold KW, Kong G, Camenga DR, et al. Trajectories of E-cigarette and conventional cigarette use among youth. Pediatrics. 2018; 141:1-7.

82. Soneji S, Barrington-Trimis JL, Wills TA, et al. Association between initial use of e-cigarettes and subsequent cigarette smoking among adolescents and young adults: a systematic review and meta-analysis. JAMA Pediatr. 2017;171:788-97

83. Corey CG, Ambrose BK, Apelberg BJ, King BA. Flavored tobacco product use among middle and high school students-United States, 2014. MMWR Morb Mortal Wkly Rep. 2015;64:1066-70

84. Dai H, Hao J. Flavored electronic cigarette use and smoking among youth. Pediatrics. 2016;138:1-8.

85. Food and Drug Administration, HHS. Deeming tobacco products to be subject to the federal food, drug, and cosmetic act, as amended by the family smoking prevention and tobacco control act; restrictions on the sale and distribution of tobacco products and required warning statements for tobacco products. Final rule. Fed Regist. 2016;81:28973-9106

86. Brown J, Beard E, Kotz D, Michie S, West R. Real-world effectiveness of e-cigarettes when used to aid smoking cessation: a cross-sectional population study. Addiction. 2014;109. $1531-40$ 